\title{
COMMUTING AND SEMI-COMMUTING TOEPLITZ OPERATORS ON THE WEIGHTED HARMONIC BERGMAN SPACE
}

\author{
Linghui Kong* ${ }^{*}$ ShuAng Qu And Shan TONG
}

Abstract. In this article, we show that two Toeplitz operators on the weighted harmonic Bergman space can commute only in the trivial case under certain conditions. The triviality here means a nonzero linear combination of their symbols is constant. Moreover, we give a characterization of semi-commuting Toeplitz operators with harmonic or analytic symbols. Mathematics subject classification (2010): 47B35, 47B38.

Keywords and phrases: Toeplitz operators, weighted Bergman space, commuting, semi-commuting.

\section{REFERENCES}

[1] S. Axler, P. Bourdon, And W. Ramey, Harmonic function theory, Springer-Verlag, New York, 1992.

[2] S. AXler AND Ž. ČUČKOVIĆ, Commuting Toeplitz operators with harmonic symbols, Integr. equ. oper. theory 14, 1 (1991), 1-12.

[3] S. AXler, Ž. ČUČKOVIĆ, AND N. RAO, Commutants of analytic Toeplitz operators on the Bergman space, Proc. Amer. Math. Soc. 128, 7 (2000), 1951-1953.

[4] B. Choe, H. Koo, And Y. LeE, Commuting Toeplitz operators on the polydisk, Trans. Amer. Math. Soc. 356, 5 (2004), 1727-1749.

[5] B. ChoE, And Y. LEE, Commuting Toeplitz operators on the harmonic Bergman space, Michigan Math. J. 46, 1 (1999), 163-174.

[6] B. CHOE, AND Y. LEE, Pluriharmonic symbols of essentially commuting Toeplitz operators, Illinois J. Math. 42, 2 (1998), 280-293.

[7] B. ChoE, AND K. NAM, Note on commuting Toeplitz operators on the pluriharmonic Bergman space, J. Korean Math. Soc. 43, 2 (2006), 259-269.

[8] Ž. ČUČKOVIĆ AND N. RAO, Mellin transform, monomial symbols, and commuting Toeplitz operators, J. Funct. Anal. 154, 1 (1998), 195-214.

[9] Y. LEE, Pluriharmonic symbols of commuting Toeplitz type operators on the weighted Bergman spaces, Canad. Math. Bull. 41, 2 (1998), 129-136.

[10] Y. LEE, AND K. ZHU, Some differential and integral equations with applications to Toeplitz operators, Integr. equ. oper. theory 44, 4 (2002), 466-479.

[11] I. Louhichi, AND L. ZAKARIASy, On Toeplitz operators with quasihomogeneous symbols, Arch. Math. 85, 3 (2005), 248-257.

[12] Y. Lu, Commuting of Toeplitz operators on the Bergman space of the bidisc, Bull. Austral. Math. Soc. 66, 2 (2002), 345-351.

[13] S. OHno, Toeplitz and Hankel operators on the harmonic Bergman space, RIMS Kokyuroku, 946 (1996), 25-34.

[14] K. Stroethoff, Essentially commuting Toeplitz operators with harmonic symbols, Can. J. Math. 45, 5 (1993), 1080-1093.

[15] D. Zheng, Commuting Toeplitz operators with pluriharmonic symbols, Trans. Amer. Math. 350, 4 (1998), 1595-1618.

[16] K. ZHU, Duality of Bloch spaces and norm convergence of Taylor series, Michigan Math. J. 38, 1 (1991), 89-101. 